\title{
In vitro assembly of bacteriophages: folding, kinetic control and intermediates
}

\author{
ROMAN TUMA $\dagger^{*}$, HIRO TSURUTA $\ddagger$, PETER E. PREVELIGE§, DENIS E. KAINOV $\dagger$, MINNA M. PORANEN $\dagger$ and DENNIS \\ H. BAMFORD $\dagger$
}

\begin{abstract}
$\dagger$ Institute of Biotechnology and Faculty of Bioscience, Biocentre 3, Helsinki FIN-00014, Finland
$¥$ Stanford Synchrotron Radiation Laboratory, Stanford University, Palo Alto, USA

$\S$ Department of Microbiology, University of Alabama at Birmingham, Birmingham, USA
\end{abstract}

Bacteriophage P22 serves as a model for the assembly and maturation of other icosahedral double-stranded DNA viruses. P22 coat and scaffolding proteins assemble into a procapsid which subsequently expands during DNA packaging (maturation). Assembly and maturation is accompanied by coat protein folding [1]. In the presented experiments in vitro assembly was initiated by a rapid mixing of monomeric coat protein with different engineered scaffolding proteins. Assembly was followed by time-resolved small angle X-ray scattering. The scattering curves revealed that a slower nucleation phase was followed by a rapid assembly of closed shells when the wild type scaffolding protein was used. On the other hand, an engineered covalent dimer of the scaffolding protein accelerated the nucleation step and resulted in a rapid polymerization that yielded a polydisperse mixture of incomplete shells. Thus, the outcome of polymerization is determined by the ratio of the nucleation and elongation rates. The nucleation and elongation rates can be modulated by the oligomeric state of the scaffolding protein (e.g. dimerization equilibrium). These experiments indicated that P22 assembly is under kinetic control.

Double-stranded RNA viruses infecting bacterial hosts belong to the Cystoviridae family (bacteriophages $\phi 6-$ $\phi 14)$ and share structural as well as functional similarities with dsRNA viruses infecting eukaryotic hosts (e.g. L-A, rotavirus, bluetongue virus, and reovirus) [2]. The first step on the assembly pathway is the procapsid formation, for which in vitro systems have been developed [3, 4]. The procapsid is composed of major structural protein $\mathrm{P} 1$ (120 copies), RNA-dependent RNA polymerase P2 (12 copies), 12 hexamers of the packaging ATPase P4, and 30 dimers of assembly factor P7 [2]. The in vitro assembly systems have been instrumental in revealing assembly intermediates and conformational changes [3-5]. The two enzymes that are associated with the procapsid (P2 and $\mathrm{P} 4)$ play essential role in nucleation and stabilization of early assembly intermediates $[3,4]$. The nucleation complex contains one or more $\mathrm{P} 1$ tetramers and is further stabilized by $\mathrm{P} 4$ hexamers. Interaction of P1 and P4 during assembly is accompanied by a folding event [5], a feature common with the P22 assembly. P4 protein also stabilizes onpathway intermediates and limits off-pathway aggregation [4], a feature similar to the P22 scaffolding protein.

In summary, coat protein assembly in more complex bacteriophage proceeds via a nucleation step, which is controlled by other viral proteins. The polymerization reaction is coupled to capsid protein folding and cannot be considered as a simple sequence of reversible associations. The final outcome of assembly seems to depend on the intermediates rather than preference for icosahedral symmetry or stability of the final structure.

\section{References}

[1] Tuma, R., Tsuruta, H., Benevides, J.M., Thomas, G.J., Jr. and Prevelige, P.E., Jr., 2001, A conformational change accompanies the assembly of bacteriophage P22 coat protein. Biochemistry, 40, 665-674.

[2] Poranen, M.M. and Tuma, R., 2004, Self-assembly of doublestranded RNA bacteriophages. Virus Res., 101, 93-100.

[3] Poranen, M.M., Paatero, A.O., Tuma, R. and Bamford, D.H., 2001, Self-assembly of a viral molecular machine from purified protein and RNA constituents. Mol. Cell., 7, 845-854.

[4] Kainov, D.K., Butcher, S.J., Bamford, D.H. and Tuma, R., 2003, Conserved intermediates on the assembly pathway of dsRNA bacteriophages. J. Mol. Biol., 328, 791-804.

[5] Benevides, J.M., Juuti, J.T., Tuma, R., Bamford, D.H. and Thomas, G.J., Jr., 2002, Characterization of subunit-specific interactions in a double-stranded RNA virus: Raman difference spectroscopy of the 6 procapsid. Biochemistry, 41, 11946-11953.

*Corresponding author. Address: Institute of Biotechnology University of Helsinki, Finland 


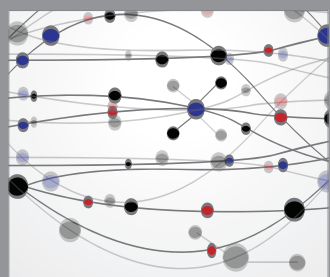

The Scientific World Journal
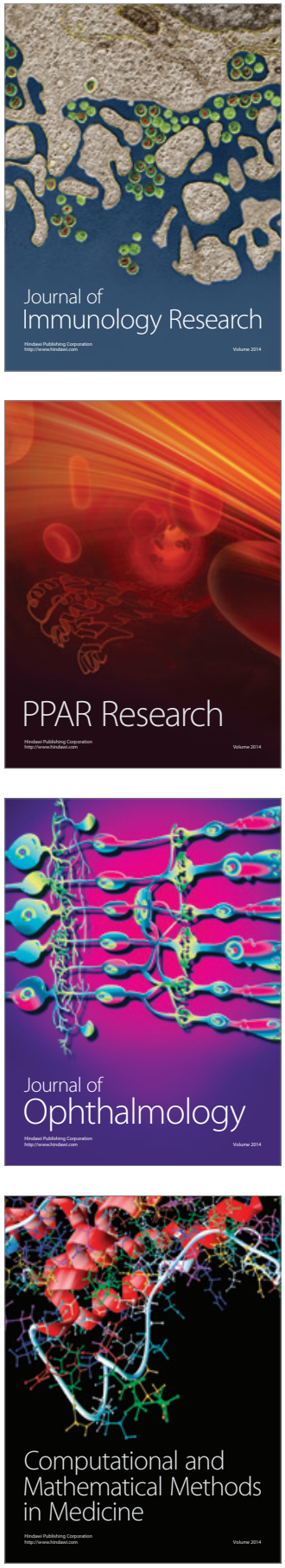

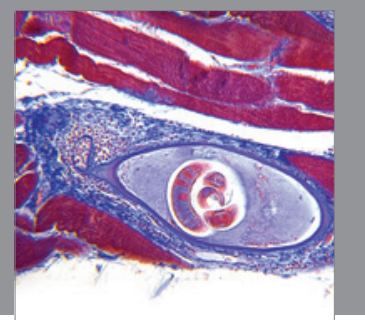

Gastroenterology

Research and Practice
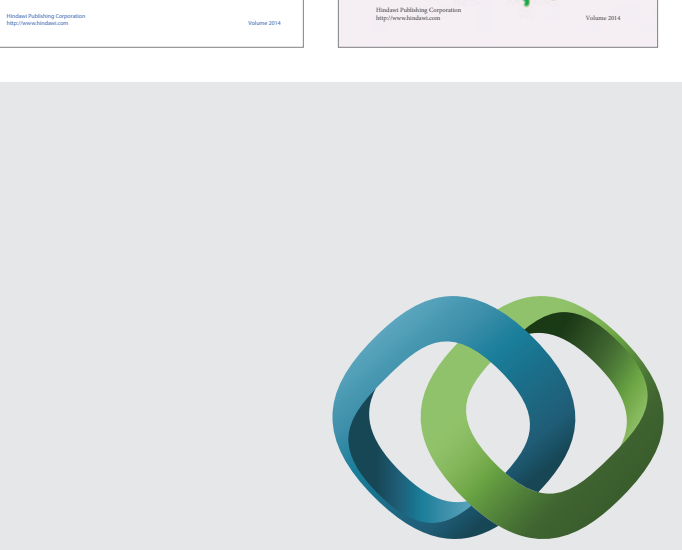

\section{Hindawi}

Submit your manuscripts at

http://www.hindawi.com
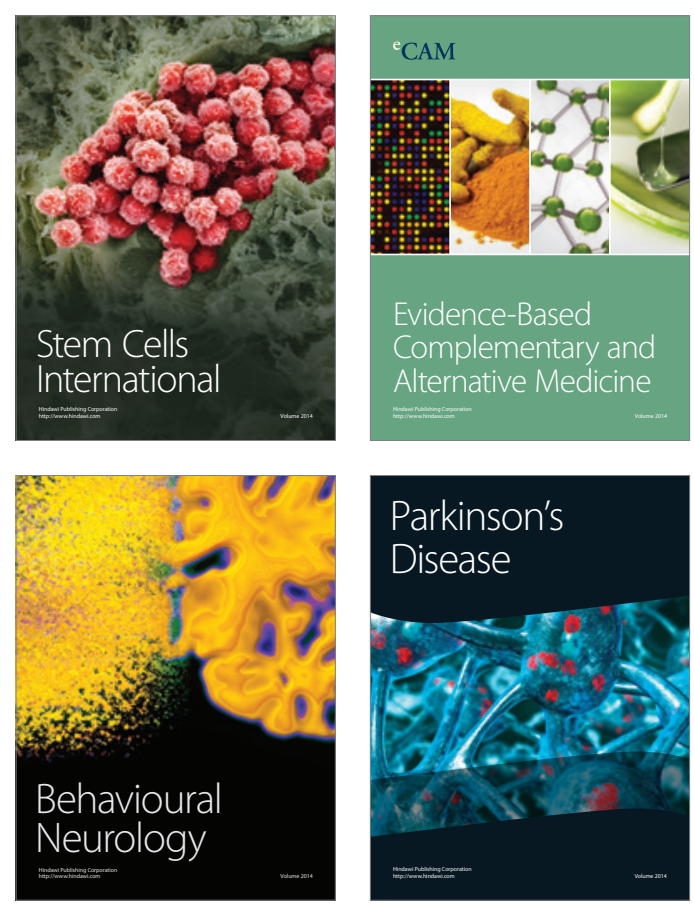

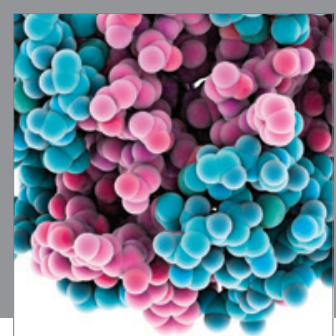

Journal of
Diabetes Research

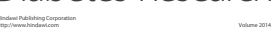

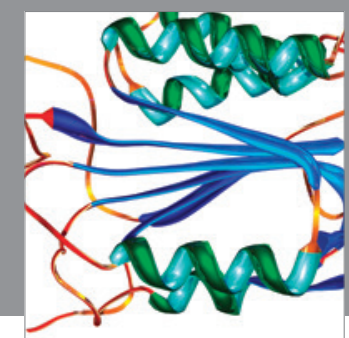

Disease Markers
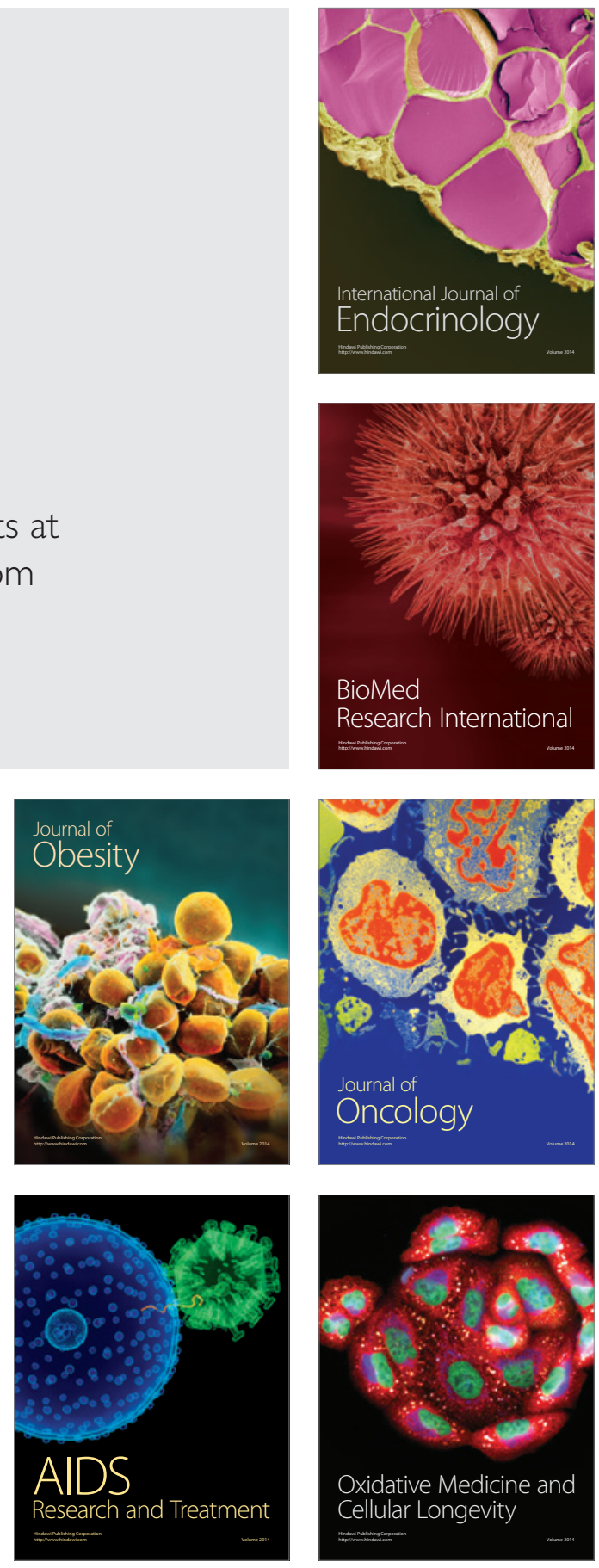